PROCEEDINGS OF THE

AMERICAN MATHEMATICAL SOCIETY

Volume 35, No. 1, September 1972

\title{
EXISTENCE OF A SEMINORMAL BASIS IN $C[0,1]$
}

\section{SHERWOOD SAMN}

\begin{abstract}
The existence of a basis in $C[0,1]$ consisting of pairwise orthogonal elements is established.
\end{abstract}

1. Introduction. Let $B$ be a real Banach space. $x \in B$ is orthogonal to $y \in B$, written $x \perp y$, if $\|x+b y\| \geqq\|x\|$ for all real numbers $b$. $x \in B$ is orthogonal to a subset $S$ of $B$, written $x \perp S$, if $x \perp y$ for all $y \in S$. A basis $\left\{x_{i}\right\}$ of $B$ is normal if, for all $i=1,2, \cdots,\left\|x_{i}\right\|=1$ and $x_{i} \perp$ $\left[x_{1}, x_{2}, \cdots, x_{i-1}, x_{i+1}, \cdots\right]$, the closed subspace of $B$ spanned by $x_{1}, x_{2}, \cdots$. A basis of $B$ is seminormal if $\left\|x_{i}\right\|=1$ and $x_{i} \perp x_{j}$ for all $i \neq j$. Clearly every normal basis is a seminormal basis. The converse of this is not true in general. The problem of existence of a normal basis in $C[0,1]$ would be solved in the negative if the nonexistence of a seminormal basis in $C[0,1]$ is proved. However, we will show in this note that $C[0,1]$ does possess a seminormal basis.

2. Main result. Let $a_{0}=0, a_{1}=1$, and if $j=2^{n}, a_{j+k}=(2 k-1) /(2 j)$ $\left(n=0,1,2, \cdots ; k=1,2, \cdots, 2^{n}\right)$. We define a sequence $\left\{x_{i}\right\}$ in $C[0,1]$ as follows:

$$
\begin{aligned}
x_{0}(t) & =1, & & t=a_{0}, \\
& =0, & & t \in\left\{a_{1}, a_{2}\right\}, \\
& =\text { linear, } & & \text { for other } t, \\
x_{1}(t) & =1, & & t=a_{1}, \\
& =0, & & t \in\left\{a_{0}, a_{2}\right\}, \\
& =\text { linear, } & & \text { for other } t,
\end{aligned}
$$

and, for $j=2^{n}\left(n=0,1, \cdots ; k=1, \cdots, 2^{n}\right)$,

$$
\begin{aligned}
x_{j+k}(t) & =0, & & t \in\left\{a_{0}, a_{1}, \cdots, a_{j}, b_{j}\right\}, \\
& =1, & & t \in\left\{a_{j+1}, \cdots, a_{j+k}\right\}, \\
& =-1, & & t \in\left\{a_{j+k+1}, \cdots, a_{2 j}\right\}(=\approx, \text { if } k=j), \\
& =\text { linear, } & & \text { for the other } t,
\end{aligned}
$$

Received by the editors January 13, 1972.

AMS 1970 subject classifications. Primary 46B15; Secondary 46E15.

c. American Mathematical Society 1972 
where

$$
\begin{aligned}
b_{j} & =a_{2 j+1}, & & \text { if } n \text { is even, } \\
& =a_{4 j}, & & \text { if } n \text { is odd. }
\end{aligned}
$$

ThEOREM. $\left\{x_{\imath}\right\}$ is a seminormal basis of $C[0,1]$.

Obviously, $\left\|x_{\imath}\right\|=1$. We need only show $x_{i} \perp x_{j}(i \neq j)$ and $\left\{x_{i}\right\}$ is a basis of $C[0,1]$.

3. Orthogonality. The fact that $x_{i} \perp x_{j}(i \neq j)$ follows from the following:

Proposition. Let $x, y \in C[0,1]$. Suppose $\{t \in[0,1]:|x(t)|=\|x\|\}=$ $\left\{t_{1}, \cdots, t_{n}\right\}$. Then $x \perp y$ if and only if $y\left(t_{i}\right) x\left(t_{i}\right) y\left(t_{j}\right) x\left(t_{j}\right) \leqq 0$ for some $1 \leqq i, j \leqq n$.

Proof. The condition is clearly sufficient. On the other hand, suppose $y\left(t_{i}\right) x\left(t_{i}\right) y\left(t_{j}\right) x\left(t_{j}\right)>0$ for all $1 \leqq i, j \leqq n$. Then $y\left(t_{i}\right) x\left(t_{i}\right)$ have the same sign, say positive, for all $i=1,2, \cdots, n$. By the continuity of $x$ and $y$, there exist positive numbers $p$ and $q$, and a closed subset $F$ of $[0,1]$ such that $\left\{t_{1}, \cdots, t_{n}\right\} \subset F,|x(t)| \leqq\|x\|-p$ for $t \in[0,1] \backslash F,|x(t)| \geqq \frac{1}{2}$ for $t \in F$, and $|y(t)| \geqq q>0$ for $t$ in $F$. Hence $\|x+b y\|<\|x\|$ if $b=-(p /(2\|y\|))$.

Corollary. If $x \in C[0,1]$ is such that $n=1$ in the Proposition, then $x \perp y$ if and only if $y\left(t_{1}\right)=0$.

4. $\left\{x_{i}\right\}$ is a basis. We will show this in two steps:

A. We construct a basis $\left\{y_{i}\right\}$ of $C[0,1]$ from the Schauder basis $\left\{z_{i}\right\}$ of $C[0,1]$.

B. We construct $\left\{x_{i}\right\}$ from $\left\{y_{i}\right\}$

The following method of piecewise construction of new basis in Banach space is important for our purpose here. The proof can be found in [1, p. 64].

Lemma. Let $\left\{z_{n}\right\}$ he a basis of a Banach space $E,\{m(n)\}$ an increasing sequence of positive integers, $m(0)=0$, and $\left\{y_{n}\right\}$ a sequence in $E$ such that

(a) $\left[y_{m(n-1)+1}, \cdots, y_{m(n)}\right]=\left[z_{m(n-1)+1}, \cdots, z_{m(n)}\right](n=1,2, \cdots)$, and

(b) there exists a positive constant $C$ such that

$$
\left\|\sum_{i}^{j} c_{i} y_{i}\right\| \leqq C\left\|\sum_{i=m(n-1): 1}^{m(n)} c_{i} y_{i}\right\|
$$

for any sequence $\left\{c_{i}\right\}$ of real numbers, and $m(n-1)+1 \leqq j \leqq m(n)(n=1$, $2, \cdots)$.

Then $\left\{y_{i}\right\}$ is a basis of $E$. 
4A. Let $\left\{z_{i}\right\}$ be the Schauder basis of $C[0,1]$, i.e., $z_{0}(t)=1-t, z_{1}(t)=t$, and, for $j=2^{n}\left(n=0,1, \cdots ; k=1,2, \cdots, 2^{n}\right)$,

$$
\begin{aligned}
z_{j+k}(t) & =0, & & t \in\left\{a_{0}, a_{1}, \cdots, a_{j}\right\}, \\
& =1, & & t=a_{j+k}, \\
& =\text { linear, }, & & \text { for the other } t .
\end{aligned}
$$

Now define a sequence $\left\{y_{i}\right\}$ as follows: $y_{0}(t)=x_{0}(t), y_{1}(t)=x_{1}(t)$, and, for $j=2^{n}\left(n=0,1, \cdots ; k=2,3, \cdots, 2^{n}\right)$,

$$
\begin{aligned}
& y_{j+1}(t)=\frac{1}{2}\left(x_{j+1}(t)+x_{2 j}(t)\right), \\
& y_{j+k}(t)=\frac{1}{2}\left(x_{j+k}(t)-x_{j+k-1}(t)\right) .
\end{aligned}
$$

It is not hard to see the following is true: $\left[y_{0}, \cdots, y_{3}\right]=\left[z_{0}, \cdots, z_{3}\right]$, and, for $j=2^{2 n}(n=1,2, \cdots)$,

$$
\left[y_{j}, \cdots, y_{2 j+1}\right]=\left[z_{j}, \cdots, z_{2 j+1}\right], \quad y_{i}=z_{i}(i=2(j+1), \cdots, 4 j-1) .
$$

Now let $\left\{c_{i}\right\}$ be any sequence of real numbers. Set $b_{i}=\left|c_{i}\right|(i=0,1,2)$ and $b_{3}=\left|c_{3}+\frac{1}{2} c_{0}\right|$, then

$$
\begin{aligned}
\left\|\sum_{i=0}^{3} c_{i} y_{i}\right\| & =\max \left\{b_{k}: 0 \leqq k \leqq 3\right\} \geqq \max \left\{b_{k}: 0 \leqq k \leqq j \leqq 3\right\} \\
& =\left\|\sum_{i=0}^{j} c_{i} y_{i}\right\| \quad(0 \leqq j \leqq 3) .
\end{aligned}
$$

And for $j=2^{2 n}(n=1,2, \cdots)$, set $b_{i}=\left|c_{i}\right|(i=j, j+1, j+2, \cdots, 2 j-2,2 j$, $2 j+1)$ and $b_{2 j-1}=\left|c_{2 j-1}+\frac{1}{2} c_{j}\right|$. Then

$$
\begin{aligned}
\left\|\sum_{k=0}^{j+1} c_{j+k} y_{j+k}\right\| & =\max \left\{b_{k+j}: 0 \leqq k \leqq j+1\right\} \\
& \geqq \max \left\{b_{k+j}: 0 \leqq k \leqq m \leqq j+1\right\} \\
& =\left\|\sum_{k=0}^{m} c_{j+k} y_{j+k}\right\| \quad(0 \leqq m \leqq j+1) .
\end{aligned}
$$

Hence by the Lemma cited above, $\left\{y_{i}\right\}$ is a basis of $C[0,1]$.

4B. From the definition of $x_{i}$ and $y_{i}$, it follows that $x_{i}=y_{i}(i=0,1,2)$ and $\left[x_{j+1}, \cdots, x_{2 j}\right]=\left[y_{j+1}, \cdots, y_{2 j}\right]\left(j=2^{n}, n=1,2, \cdots\right)$. Again let $\left\{c_{i}\right\}$ be any sequence of real numbers. For $j=2^{2 n}(n=1,2, \cdots)$ and $m$ a positive 
integer $\leqq j$, let

then

$$
\begin{aligned}
& b_{1}=\sum_{i=1}^{m} c_{j+i}, \quad d_{1}=\sum_{i=m+1}^{j} c_{j+i}, \\
& b_{k}=-\sum_{i=1}^{k-1} c_{j+i}+\sum_{i=k}^{m} c_{j+i} \quad(k=2, \cdots, m), \\
& d_{k}=-\sum_{i=m+1}^{m+k-1} c_{j+i}+\sum_{i=m+k}^{j} c_{j+i} \quad(k=2, \cdots, j-m),
\end{aligned}
$$

$$
\begin{aligned}
\left\|\sum_{i=1}^{j} c_{j+i} x_{j+i}\right\| & =\max \left\{\left|b_{1}+d_{1}\right|,\left|b_{2}+d_{1}\right|, \cdots,\left|b_{m}+d_{1}\right|,\right. \\
& \left.\left|-b_{1}+d_{1}\right|,\left|-b_{1}+d_{2}\right|, \cdots,\left|-b_{1}+d_{j-m}\right|\right\} \\
& \geqq \max \left\{\left|b_{1}+d_{1}\right|,\left|b_{2}+d_{1}\right|, \cdots,\left|b_{m}+d_{1}\right|,\left|-b_{1}+d_{1}\right|\right\} \\
& \geqq \inf \left\{\max \left\{\left|b_{1}+r\right|,\left|b_{2}+r\right|, \cdots,\left|b_{m}+r\right|,\left|-b_{1}+r\right|\right\}\right\} \\
& =\frac{1}{2}\left(\max \left\{\left|b_{1}\right|, \cdots,\left|b_{m}\right|\right\}+|B|\right) \geqq \frac{1}{2} \max \left\{\left|b_{1}\right|, \cdots,\left|b_{m}\right|\right\} \\
& =\frac{1}{2}\left\|\sum_{i=1}^{m} c_{j+i} x_{j+i}\right\|,
\end{aligned}
$$

where $B=\max \left\{b_{1}, \cdots, b_{m}\right\}$ if $\max \left\{\left|b_{i}\right|: 1 \leqq i \leqq m\right\}=-b_{k}$ for some $k$, $1 \leqq k \leqq m$; or $B=\min \left\{b_{1}, \cdots, b_{m}\right\}$ if $\max \left\{\left|b_{i}\right|: 1 \leqq i \leqq m\right\}=b_{k}$ for some $k$, $1 \leqq k \leqq m$. This completes the proof.

\section{REFERENCE}

1. I. Singer, Bases in Banach spaces. I, Springer, Berlin and New York, 1970.

Department of Mathematics, Indiana and Purdue Universities at Indianapolis, INDIANAPOLIS, INDIANA 46205 